\title{
GUILHERME DE OCKHAM E O ARGUMENTO ANSELMIANO VIA ESCOTO
}

\author{
Maria Leonor L. O. Xavier \\ Universidade de Lisboa
}

Por certo não alheio à influência das religiões monoteístas na história do pensamento ocidental, o tema de Deus tornou-se de tal modo incontornável que deveio um motivo maior de exigência e de elevação da especulação filosófica na Idade Média. Todos os grandes filósofos especulativos medievais são pensadores do tema de Deus. Guilherme de Ockham não é uma excepção, não obstante o seu cepticismo teológico. Anselmo, entretanto, já se tinha tornado um marco inolvidável, como pensador do tema de Deus, dado que o seu argumento do Proslogion não conseguiu deixar indiferente a posteridade, chamando continuadamente os filósofos à colação numa história de prós e contras que se prolonga até aos dias de hoje. Guilherme de Ockham também não foge à regra. Todavia, a recepção do argumento anselmiano pelo filósofo de Ockham complica-se com a mediação de João Duns Escoto. O Doutor Subtil já se tinha pronunciado favoravelmente sobre o argumento anselmiano, interpretando-o a seu modo e integrando-o nas suas vias de demonstração da infinitude de Deus. O confrade de Ockham é um crítico incisivo das vias escotistas de demonstração do atributo divino da infinitude, e, por arrastamento, é também um crítico do argumento anselmiano, enquanto este faz parte daquelas vias. Mas significa isso que Guilherme rejeita pura e simplesmente o argumento anselmiano? Não é esse o nosso parecer. Julgamos mesmo que Guilherme de Ockham até recupera este legado de Anselmo, mas não sem despojá-lo de alguns elementos da apropriação escotista. O filósofo de Ockham recupera o legado de Anselmo, restituindo-o como um argumento a favor da existência de Deus, mas demitindo-o como um argumento a favor da infinitude divina. Tal é o que tencionamos mostrar neste nosso estudo.

Para esse efeito, a nossa análise avançará em dois principais desen-

Philosophica, 34, Lisboa, 2009, pp. 309-332 
volvimentos: o primeiro visa o conceito de Deus, porquanto Guilherme de Ockham é um dos pensadores mais penetrantes da natureza dos conceitos que formamos acerca de Deus, nomeadamente, dos conceitos já criticamente pensados ou construídos por Anselmo; o segundo revisita o argumento anselmiano - a ratio Anselmi, segundo os dois filósofos franciscanos aqui em consideração - situando-o na esteira da posição de Guilherme sobre a questão da demonstrabilidade da proposição «Deus existe». Quanto às obras a convocar: em primeiro plano, de Guilherme de Ockham, Ordinatio I e Quodlibeta Septem (I, V e VII); em segundo plano, de João Duns Escoto, Ordinatio I e Tractatus de Primo Principio; e, em plano de fundo, de Anselmo, Monologion e Proslogion.

\section{O conceito de Deus}

A fim de compreendermos a natureza dos conceitos que formamos acerca de Deus, tome-se a questão da cognoscibilidade de Deus ${ }^{1}$, a propósito da qual, Guilherme de Ockham introduz alguns elementos da sua teoria geral do conhecimento.

Neste âmbito geral, há desde logo dois possíveis modos de conhecimento a distinguir: ou algo pode ser conhecido em si ou algo pode ser conhecido num conceito próprio. Algo pode ser conhecido em si, quando nada para além da sua natureza determina o acto de inteligência em que é conhecido. O modo de conhecimento de algo em si é o modo exclusivo do conhecimento de algo, no qual nada de outro ou de estranho se mistura com a natureza desse algo. Na realidade, este modo de conhecimento não se aplica senão a uma parte restrita dos cognoscíveis, a saber, os acidentes sensíveis, como o calor, cuja natureza determina exclusiva e imediatamente o seu conhecimento intuitivo. Mas o calor é um acidente do fogo, e o conhecimento do fogo, enquanto substância, já não é o conhecimento de algo em si; é o conhecimento de algo num conceito próprio, caso em que o conhecimento da existência (quia est) precede o da quididade (quid est $)^{2}$. Importa ainda saber se as substâncias sensíveis, como o fogo, são

1 «Utrum divina essentia sit a nobis cognoscibilis» In Librum Primum Sententiarum Ordinatio I, d.3, q.2 (texto da ed. de Stephanus Brown e Gedeone Gál, in GUILLELMI DE OCKHAM Opera Theologica II, St. Bonaventure, N. Y., 1970, p. 393).

2 «Ideo dico aliter ad quaestionem quod aliqua res potest cognosci in se, ita quod nihil aliud, nec distinctum ratione nec distinctum ex natura rei, terminet actum intelligendi nisi ipsamet, et hoc sive cognoscatur abstractive sive intuitive. Aliter potest aliquid intelligi non in se sed in aliquo conceptu sibi proprio, et hoc maxime est verum quando cognoscitur ille conceptus de aliquo ente verificari. Et sic intelligendum est dictum Philosophi II Posteriorum [93a 16-20], ubi vult quod aliquando simul habetur cognitio de 'quia est' et 'quid est' et aliquando ante cognoscitur 'quia est' quam 'quid est'; quando enim res in se cognoscitur simul cognoscitur 'quia est' 
cognoscíveis em conceitos próprios e simples. A resposta de Guilherme de Ockham é não, porque, se as substâncias sensíveis fossem cognoscíveis em conceitos próprios e simples, teria de haver um conceito para cada substância individual, o que não acontece, uma vez que os conceitos simples que temos das substâncias sensíveis não são particulares, mas são comuns, como são os conceitos genéricos e específicos ${ }^{3}$. Por conseguinte, o conhecimento de algo em conceito próprio não se dá também sem restrições, porquanto não é de facto um modo de conhecimento de algo em conceito próprio e simples, mas apenas um modo de conhecimento de algo em conceito próprio e compósito.

Se tal é o caso das substâncias sensíveis, tal é a fortiori o caso de Deus, que não é uma substância sensível, e, portanto, não é senão ainda mais indirectamente cognoscível.

Elimine-se então desde logo a possibilidade de um conhecimento de Deus em si por nós, porque Deus não é por nós cognoscível como um acidente sensível. Com efeito, Deus não é por nós intuitivamente cognoscível como o conhecimento em si dos acidentes sensíveis, que depende de uma intuição sensível dos mesmos. Além disso, Deus não é por nós intuitivamente cognoscível a partir de uma experiência intuitiva dos sensíveis ${ }^{4}$. Deus só é por nós abstractivamente cognoscível a partir dessa expe-

et 'quid est', quia ipsa res non potest cognosci nisi ipsa quidditas vel saltem aliqua pars quidditatis in se cognoscatur. De hoc tamen alias erit sermo [infra, p. 414]. Quando autem tantum cognoscitur in aliquo conceptu sibi proprio, prius cognoscitur 'quia est' quam 'quid est', hoc est, antequam quidditas vel quaecumque pars quidditatis vel quodcumque simplex sibi proprium cognoscatur cognitione sibi propria vel aequivalenti, sicut videndo ignem cognoscitur et quia est ignis et quid est ignis; et hoc si ignis in se cognosceretur, sed de facto non cognoscitur in se nisi accidens ignis, tamen ipse calor simul cognoscitur quia est et quid est. Et ita est de omnibus accidentibus quae immediate terminant actum intelligendi; sed de aliis quae non sic cognoscuntur, prius cognoscitur quia est quam quid est, sicut prius cognoscitur quod aliquid interponitur inter solem et lunam quam cognoscatur quid interponitur.» Ord. I, d.3, q.2 (Brown Gál: p. 401, 11.15-23, p. 402, 11.1-16).

3 «Quarto dico quod intellectus noster de nulla creatura potest habere aliquem talem conceptum simplicem proprium sine visione creaturae nec cum visione; et hoc quia quaelibet talis cognitio sive conceptus aequaliter est similitudo et repraesentat omnia individua simillima, et ita non plus est conceptus proprius unius quam alterius.» Quodlibet V, q.7, c.4 (Quodlibeta Septem, texto da ed. de Joseph C. Wey, in GUILLELMI DE OCKHAM Opera Theologica IX, St. Bonaventure, N. Y.St. Bonaventure, N. Y., 1980, p. 506, 11.63-68).

4 «Per hoc dico ad quaestionem quod nec divina essentia, nec divina quidditas, nec aliquid intrinsecum Deo, nec aliquid quod est realiter Deus potest in se cognosci a nobis, ita quod nihil aliud a Deo concurrat in ratione obiecti.» Ord. I, d.3, q.2 (Brown e Gál: p. 402, 11.17-20). Justificação: «Primum patet, quia nihil potest cognosci naturaliter in se nisi praecognoscatur intuitive; sed Deus non potest cognosci a nobis intuitive ex puris naturabilibus, igitur etc. Minor est manifesta. Maiorem probo, quia non est maior ratio quod una res possit a nobis cognosci in se sine notitia intuitiva praevia quam alia; sed multae res non sunt cognoscibiles nisi praevia 
riência, do que não resulta um conhecimento de Deus em si, mas sim um conhecimento de Deus em conceito.

Que tipo de conceito é esse que podemos formar acerca de Deus? É um conceito próprio mas compósito, cujas partes são conceitos simples naturalmente abstraíveis das coisas ${ }^{5}$. O nosso conceito possível de Deus é, pois, um conceito próprio mas composto de conceitos comuns a Deus e a outras realidades. Tal como as restantes realidades, Deus é por nós cognoscível com base em conceitos comuns. Mais: Deus não é por nós concebível senão com base em conceitos comuns ${ }^{6}$. Em virtude de ser um conceito constituído por conceitos comuns, o nosso conceito possível de Deus é um conceito formado a posteriori. Em virtude de ser um conceito formado pela conjunção simultânea de múltiplos conceitos comuns, o nosso conceito possível de Deus é um conceito próprio de Deus, isto é, que a nenhuma outra entidade se adequa. Que conceitos comuns são, então, esses que fazem parte do nosso conceito possível de Deus? São conceitos, como o de ente, que é abstraído dos entes e é comum a Deus e aos outros entes; como o de sabedoria, que é comum àquela que é criada e àquela que é incriada; ou como o de bondade, que é também comum àquela que é criada e àquela que é incriada; e como todos os outros conceitos, que possam incluir o criado e o incriado, os conceitos transcendentais. A conjunção simultânea de todos esses conceitos produz um conceito único, que é o nosso conceito possível e próprio de Deus ${ }^{7}$. Este

notitia intuitiva, quia, secundum Philosophum [Physica II, 193 ${ }^{\text {a } 6-9], ~ c a e c u s ~ a ~ n a t i-~}$ vitate non potest habere scientiam de coloribus nec potest cognoscere colorem in se, quia non potest cognoscere colorem intuitive. Igitur universaliter nulla res potest in se cognosci nisi praecognoscatur intuitive; et si creatura non potest cognosci in se nisi primo cognoscatur intuitive, multo magis nec Deus.» Ord. I, d.3, q.2 (Brown e Gál: p. 403, 11.5-16).

5 «Secundo, dico quod essentia divina vel quidditas divina potest cognosci a nobis in aliquo conceptu sibi proprio, composito tamen, et hoc in conceptu cuius partes sunt abstrahibiles naturaliter a rebus. Ord. I, d.3, q.2 (Brown e Gál: p. 402, 11.20-22, p. 403, 1.1).

6 «Secundum patet, quia sicut creatura potest cognosci in conceptu aliquo communi simplici, ita potest Deus, quia aliter nullo modo esset a nobis cognoscibilis.» Ord. I, d.3, q.2 (Brown e Gál: p. 403, 11.17-19).

7 «Sed nunc est ita quod quando sunt multa communia habentia aliquod idem contentum, omnia illa communia simul accepta faciunt unum proprium illi, quia ex quo sunt distincta communia, oportet quod aliquid contineatur sub singulo quod sub nullo aliorum continetur, igitur omnia illa communia simul accepta nulli alii possunt convenire. Sed nunc est ita quod sunt multi conceptus simplices naturaliter abstrahibiles quorum quilibet est communis Deo et alicui alteri, igitur omnes illi simul accepti facient unum conceptum proprium Deo, et ita cum possit cognosci quod ille conceptus de aliquo verificatur, Deus in illo conceptu cognoscetur. Verbi gratia, ab entibus potest abstrahi conceptus entis qui est communis Deo et omnibus aliis entibus, similiter potest abstrahi conceptus sapientiae qui est praecise communis sapientiae increatae et sapientiae craetae, similiter potest abstrahi conceptus bo- 
conceito próprio, composto por múltiplos conceitos comuns, não se confunde, porém, com um conhecimento de Deus em si, porque não é a natureza de Deus que determina exclusivamente aquele conceito, dado que ele inclui o conhecimento de outras coisas, através dos conceitos comuns que o constituem ${ }^{8}$.

Entretanto, conceber Deus como ente sábio, bom, justo, etc., ou seja, a partir de conceitos comuns, é situá-lo dentro dos limites do conceito generalíssimo de ente, e, portanto, dentro de uma teoria geral do ente, ou ontologia em sentido tradicional. Esta integração ontológica do tema de Deus é o paradigma ontoteológico da teologia, e é também o seu paradigma clássico. Todos os grandes teólogos de uma forma ou de outra o assumiram. Entre eles, desde logo, Anselmo. Segundo Guilherme, se Deus não fosse cognoscível em conceitos simples e comuns a outras realidades, também não seria cognoscível no conceito próprio e compósito descrito, uma vez que este não se compõe senão de conceitos comuns; «se assim não fosse, de modo nenhum seria por nós cognoscível» ${ }^{9}$, o que é uma declaração de insuperabilidade do paradigma clássico da teologia. Todavia, há filosofias e teologias na actualidade que têm tentado ultra-

nitatis qui est praecise communis bonitati divinae et bonitati creatae, et hoc secundum quod bonitas distinguitur a sapientia, et omnes isti conceptus simul non poterunt verificari nisi de solo Deo, ex quo, per positum, nulla sapientia creata est bonitas creata nec e converso. Et ita cum possit concludi quod aliquod ens est bonitas et sapientia et sic de aliis, quae vocantur attributa, sequitur quod Deus isto modo cognoscitur in conceptu composito sibi proprio. Et hoc non est aliud nisi a creaturis abstrahere multos conceptus communes Deo et creaturis, et concludere particulariter de uno conceptu simplici communi sibi et aliis unum conceptum compositum proprium Deo, sicut contingit abstrahere conceptum entis, conceptum bonitatis, sapientiae, caritatis, et sic de aliis, et contingit de ente particulariter sumpto concludere quod est bonitas, sapientia, dilectio, iustitia, et sic de aliis, et hoc est cognoscere Deum in conceptu compósito sibi proprio.» Ord. I, d.3, q.2 (Brown e Gál: p. 403, 11.19-24, p. 404, 11.1-24).

8 «Et tamen Deus in se non cognoscitur, quia aliquid aliud a Deo hic cognoscitur, quia omnes termini istius propositionis 'aliquod ens est sapientia', 'iustitia', 'caritas', et sic de aliis, sunt quidam conceptus quorum nullus est realiter Deus, et tamen omnes isti termini cognoscuntur, vel aliquid aliud a Deo ipsis cognoscitur ex quo ipsa propositio cognoscitur. Et sicut est de ista propositione, ita est de omnibus aliis nobis possibilibus.» Ord. I, d.3, q.2 (Brown e Gál: p. 404, 11.24-26, p. 405, 11.1-4).

9 «Tertium ostendo, quod omne cognoscibile a nobis aut cognoscitur in se, aut in conceptu simplici sibi próprio, aut in conceptu composito proprio, aut in conceptu communi sibi et aliis. Sed Deus aliquo modo cognoscitur a nobis, et non primis duobus modis, sicut declaratum est [supra, pp. 312ss.]; igitur tertio modo vel quarto. Et si tertio modo, oportet quod cognoscatur quarto modo, quia conceptus proprius compositus, ex quo non potest componi ex conceptibus simplicibus propriis, oportet quod componatur ex simplicibus et communibus.» Ord. I, d.2, q.9 (Brown e Gál: p. 315, 11.3-11). «[...], quia aliter nullo modo esset a nobis cognoscibilis.» Ord. I, d.3, q.2 (Brown e Gál: p. 403, 11.18-19). Vd. nota 6. 
passá-lo, denunciando-o como redutor. Mas a alternativa será clara e continuável?

De acordo com o paradigma clássico, aquele conceito próprio e compósito é, por assim dizer, o conceito axial da teologia afirmativa, visto que é formado por todos os conceitos comuns a Deus e a outros entes. Tal é o conceito compósito integral, mas diversas composições de conceitos comuns dão origem a distintos conceitos próprios e compósitos de Deus. Múltiplos conceitos próprios e compósitos são, assim, possíveis acerca de Deus ${ }^{10}$. Mas múltiplos conceitos de Deus, conjuntamente, próprios, absolutos, afirmativos e simples já não são possíveis. Guilherme de Ockham elimina, de facto, esta possibilidade mediante um exercício de análise dos tipos de conceitos possíveis acerca de Deus, que não satisfazem alguma dessas condições conjuntas: a condição de serem pelo menos dois conceitos absolutos exclui todos os conceitos conotativos, como causa primeira, criador, governador, glorificador, etc.; a condição de serem pelo menos dois conceitos afirmativos exclui todos os conceitos negativos, como incorruptível, imortal, infinito, etc.; por fim, a condição de serem pelo menos dois conceitos simples exclui todos os conceitos compósitos, como ente infinito, bem supremo, acto puro, etc. ${ }^{11}$. Cabe, então, perguntar: o que é que resta à disposição no nosso discurso conceptual? Porventura, nada mais resta. E não só dois conceitos, pois nem um só conceito nós podemos formar, que satisfaça todas as cláusulas, isto é, que seja próprio, absoluto, afirmativo e simples. Como vimos, o conceito que caracteriza o nosso conhecimento de Deus é um conceito próprio, mas não simples, porque compósito, e também não absoluto, porque conotativo, dado que conota sempre algo distinto de Deus, enquanto é formado por conceitos comuns.

Discriminados os vários tipos de conceitos, nos quais podemos conceber Deus - simples, compósitos, afirmativos, negativos, próprios e conotativos - urge agora focar aqueles conceitos de Deus, que são indissociáveis do legado anselmiano do argumento do Proslogion.

10 «Utrum de Deo possint haberi plures conceptus proprii» Quodlibet V, q.7 (Wey: p. 503, 11.1-2). «Ad argumentum principale dico quod de Deo possunt haberi plures conceptus proprii compositi formaliter et aequivalenter, sed non simplices praedicto modo.» Quodlibet V, q.7 (Wey: p. 508, 11.114-116).

11 «Ad istam quaestionem dico quod de Deo non possunt haberi plures conceptus proprii et convertibiles cum eo, quorum uterque sit absolutus non-connotativus, affirmativus non-negativus, simplex non-compositus. Per primum excluduntur tales conceptus: 'prima causa', 'creativum', 'gubernativum', 'glorificativum'. Per secundum excluduntur tales: 'incorruptibile', 'immortale', 'infinitum'. Per tertium excluduntur tales: 'ens infinitum', 'summum bonum', 'actus purus'. Sed cum omnibus istis condicionibus non potest aliquis habere duos conceptus proprios Deo quidditativos, nec unum quidditativum et alium denominativum. Et loquor de conceptu qui est cognitio abstractiva.» Quodlibet V, q.7, c.1 (Wey: p. 504, 11.12-22). 
Referimo-nos, antes de mais, ao conceito de supremo (summum), que Anselmo substitui por insuperável, através da elaboração do nome perifrástico «algo maior do que o qual nada possa ser pensado» (aliquid quo nihil maius cogitari possit), que designa Deus no argumento do Pros$\operatorname{logion}^{12}$. No tratado anterior, Monologion, o conceito de supremo é recorrentemente usado em composição com conceitos comuns, como ente, essência ou natureza, para formar conceitos compósitos de Deus, como ente supremo, essência ou natureza suprema. O conceito de essência suprema é mesmo, a nosso ver, o conceito dominante de Deus no Monologion. Mas é também já neste tratado, que o autor decompõe o conceito de supremo em dois conceitos: o de maior do que todas as coisas e o daquilo maior do que o qual nada existe. O conceito de supremo é, portanto, um duplo conceito de supremo e de insuperável. Assim o entende Anselmo nas vias do Monologion, nomeadamente, na primeira e na quarta. Na primeira via, a da ordem dos bens, o bem supremo sobreleva de tal modo os restantes que nenhum outro bem é superior a ele $^{13}$. Sucintamente: o bem supremo é de tal modo sobreeminente que é insuperável. O conceito de supremo constitui assim condição suficiente do conceito de insuperável; a insuperabilidade é uma consequência necessariamente implicada pela supremacia. Também na quarta via, a da ordem das naturezas, a natureza suprema é de tal modo superior às outras que a nenhuma outra a mesma é inferior ${ }^{14}$. De novo: a natureza suprema é de tal modo sobreeminente que é insuperável. A mesma implicação de insuperabilidade no conceito de supremacia.

João Duns Escoto veio posteriormente a adoptar e a ratificar este procedimento anselmiano nas suas vias de demonstração do primeiro princípio, deduzindo explicitamente da primazia o corolário da insuperabilidade. Nas vias da causalidade eficiente, este corolário precisa que a primeira causa eficiente não apenas é anterior às outras como não tem causa alguma anterior, pois esta entraria em contradição com a primazia e a incausabilidade daquela ${ }^{15}$. Também as vias da causalidade final são rematadas pelo corolário da insuperabilidade da primeira causa final. Este

12 «Et quidem credimus te esse aliquid quo nihil maius cogitari possit» Proslogion 2 (texto da ed. crítica de F. S. Schmitt, in ANSELMI Opera omnia, Stuttgart - Bad Cannstatt, 1968: I, p. 101, 11.4-5).

13 «Id enim summum est, quod sic supereminet aliis, ut nec par habeat nec praestantius.» Monologion 1 (Schmitt: I, p. 15, 11.9-10).

14 «Restat igitur unam et solam aliquam naturam esse, quae sic est aliis superior, ut nullo sit inferior.» Mon. 4 (Schmitt: I, p. 17, 11.24-25).

15 Cf. Ordinatio I, d.2, p. 1, q.1, n.59 (IOANNIS DUNS SCOTI Opera Omnia, Ed. Vaticana, 1950: II, p. 165); Tractatus de Primo Principio (doravante TPP), c.3, n.33 (texto da ed. de W. Kluxen, in Biblioteca de Autores Cristianos 503, Madrid, 1989 , p. 84). 
corolário determina que a primeira causa final é de tal modo primeira que é impossível que haja alguma outra precedente. Assim entendida, a insuperabilidade é uma forma intensiva da primazia, mantendo-se indissociável desta ${ }^{16}$. Por fim, também as vias escotistas da eminência são terminadas pelo corolário da insuperabilidade da natureza suprema. Este corolário denuncia a contradição entre a posição de supremacia e a hipotética superação da natureza suprema por uma natureza mais eminente ou superior $^{17}$. Deste modo, a supremacia implica a insuperabilidade, também para o Doutor Subtil.

Guilherme de Ockham, por sua vez, não deixa de reconhecer igualmente esta dupla face do conceito de supremo, classificando-o como um conceito conotativo e negativo: conotativo, enquanto nele se concebe algo que é mais nobre do que os restantes, o que corresponde ao conceito de supremo propriamente dito; negativo, enquanto nele se concebe a negação de algo mais nobre, o que corresponde ao conceito de insuperável. O conceito de supremo (summum) pode ser conotativo ou negativo e pode ser simultaneamente conotativo e negativo, constituindo o duplo conceito de supremo e de insuperável ${ }^{18}$. Assim se caracteriza, segundo Guilherme de Ockham, o conceito de Deus, que resulta quer das vias anselmianas do Monologion quer das vias escotistas do Tractatus de Primo Principio.

Todavia, já no seu primeiro tratado, Monologion, Anselmo separa as duas faces do seu duplo conceito de supremo.

Antes de mais, a crítica o conceito conotativo de supremo, como um relativo exterior à essência divina, cuja essencial grandeza não depende de relação alguma de supremacia, conduz a eliminar tal conceito do domínio dos atributos divinos. Com efeito, o conceito conotativo de supremo não satisfaz a regra anselmiana de selecção dos atributos divinos. Segundo esta regra, só aquilo que é absolutamente melhor do que a sua negação é que pode constituir um atributo da essência divina ${ }^{19}$, mas, para esta essência, não é absolutamente melhor ser suprema do que não ser suprema, uma vez

16 Cf. Ord. I, d.2, p. 1, q.1, n.63 (Ed. Vat.: II, p. 167); TPP, c.3, n.38 (BAC 503: p. 92).

17 Cf. Ord. I, d.2, p. 1, q.1, n.67 (Ed. Vat.: II, p. 168); TPP, c.3, n.39 (BAC 503: p. 94).

18 De acordo com a resposta de Guilherme à seguinte objecção: «Quartum dubium est quia videtur quod Deus potest cognosci in aliquo conceptu simplici sibi proprio qui nec sit connotativus nec negativus, sicut quod Deus est summum, et summum non est connotativum nec negativum.» Ord. I, d.3, q.2 (Brown e Gál: p. 408, 11.7-10). Resposta: "Ad quartum dico quod 'summum' dicit conceptum connotativum vel negativum vel aequivalenter dicit utrumque, quia 'summum' est aliquid quod est nobilius aliis, vel quod non habet nobilius eo.» Ord. I, d.3, q.2 (Brown e Gál: p. 416, 11.7-10).

19 «Sicut nefas est putare quod substantia supremae naturae sit aliquid, quo melius sit aliquomodo non ipsum, sic necesse est ut sit quidquid omnino melius est quam non ipsum.» Mon. 15 (Schmitt: I, p. 29, 11.17-19). 
que a suspensão da relação de supremacia em nada afecta a sua essencial grandeza ${ }^{20}$. Por conseguinte, o conceito relativo de supremo não é um conceito significativo da essência divina, pelo que não deve ser admitido, em rigor, como um atributo divino ${ }^{21}$. Traduzindo este resultado na linguagem conceptual de Guilherme de Ockham, podemos dizer que o conceito conotativo de supremo não é um conceito quiditativo de Deus.

Já o mesmo, porém não sucede ao conceito negativo de supremo, que é o de insuperável. De facto, no primeiro tratado de Anselmo, o conceito negativo de supremo fica a salvo da crítica do conotativo de supremo, dado que o conceito de insuperável constitui uma negação de relatividade a algum termo superior, o que o habilita a significar propriamente a essência divina e, portanto, a integrar o domínio dos atributos divinos. De novo, na linguagem do filósofo de Ockham, podemos dizer que o conceito de insuperável, ou o conceito negativo de supremo, é um conceito quiditativo de Deus. No entanto, como é que Anselmo reelabora o seu duplo conceito de supremo e insuperável, à luz da sua crítica do relativo supremo? Já não deduzindo a insuperabilidade como uma consequência necessariamente implicada pela supremacia, mas sim invertendo a ordem de prioridades entre os dois conceitos, de modo que conceito relativo de supremo cede prioridade ao conceito irrelativo de insuperável, como conceito próprio da essência divina. Agora, a relação de supremacia é que é aduzida à essência insuperável, como se fosse um acréscimo suspendível e separável ${ }^{22}$. Por consequência, não é já o relativo supremo, mas sim o conceito irrelativo de insuperável, aquele que se diz pelo nome perifrástico «algo maior do que o qual nada possa ser pensado» (aliquid quo nihil maius cogitari possit), e que integra consistentemente o argumento anselmiano do Proslogion.

Algo similar a esta dissociação entre supremo e insuperável também faz Guilherme de Ockham, no início dos seus Quodlibeta Septem. Logo no Quodlibet I, no âmbito da questão da demonstrabilidade ou não da

20 «Si enim nulla earum rerum umquam esset, quarum relatione summa et maior dicitur, ipsa nec summa nec maior intelligeretur: nec tamen idcirco minus bona esset aut essentialis suae magnitudinis in aliquo detrimentum pateretur.» Mon. 15 (Schmitt: I, p. 28, 11.13-16); «Patet ex eo quod summa natura sic intelligi potest non summa, ut nec summum omnino melius sit quam non summum, nec non summum alicui melius quam summum.» Mon. 15 (Schmitt: I, p. 29, 11.10-12).

21 «Si igitur summa natura sic potest intelligi non summa, ut tamen nequaquam sit maior aut minor quam cum intelligitur summa omnium: manifestum est quia summum non simpliciter significat illam essentiam quae omnimodo maior et melior est, quam quidquid non est quod ipsa.» Mon. 15 (Schmitt: I, p. 28, 11.18-22).

22 «Illa enim sola est qua penitus nihil est melius, et quae melior est omnibus quae non sunt quod ipsa est.» Mon. 15 (Schmitt: I, p. 29, 11.20-21). 
existência de um único Deus ${ }^{23}$, o filósofo começa por discernir duas descrições possíveis do nome "Deus": a de algo sumamente perfeito (aliquid nobilius et melius omni alio a se) e a de algo insuperavelmente perfeito (illud quo nihil est melius nec perfectius), isto é, o conceito conotativo e o conceito negativo de supremo na ordem da perfeição ${ }^{24}$. Vimos, segundo a Ordinatio, que o duplo conceito de supremo pode ser disjuntivo ou conjuntivo, de modo que os dois conceitos sejam separáveis ou simultaneamente admitidos. Vemos agora, segundo o Quodlibet I, que os dois conceitos estão a ser tomados separadamente. Na verdade, os dois conceitos não valem o mesmo para a questão inicial da demonstrabilidade ou não da existência de um único Deus. Esta é, aliás, uma dupla questão, na qual a questão da existência de Deus precede a questão da unicidade de Deus, de modo que esta depende daquela.

Ora, Guilherme de Ockham pronuncia-se contra a demonstrabilidade da existência de Deus, segundo a primeira descrição, isto é, como algo sumamente perfeito. Nesta acepção de Deus, a proposição «Deus existe» obtém a seguinte tripla caracterização: em primeiro lugar, não é por si evidente, dado que muitos duvidam da existência de Deus; em segundo lugar, não é demonstrável por razões por si evidentes, uma vez que toda a razão inclui algum elemento de dúvida ou de crença; em terceiro lugar, não é obviamente conhecida através da experiência ${ }^{25}$. Sucintamente, a existência de algo sumamente perfeito não é por si evidente, nem demonstrável por razões evidentes nem cognoscível pela experiência. Logo, também não será por si evidente, nem demonstrável por razões evidentes, nem cognoscível pela experiência, a unicidade de algo sumamente perfeito. Nesta posição, domina o cepticismo teológico do filósofo de Ockham.

Este cepticismo é, porém, temperado pela concessão da demonstra-

23 «Utrum possit probari per rationem naturalem quod tantum est unus Deus.»Quodlibet I, q.1 (Quodlibeta Septem, texto da ed. de Joseph C. Wey, in GUILLELMI DE OCKHAM Opera Theologica IX, St. Bonaventure, N. Y., 1980, p. 1, 11.3-4).

24 «In ista quaestione primo exponam quid intelligendum est per hoc nomen 'Deus'; secundo, respondebo ad quaestionem.» Quodlibet I, q.1 (Wey: p. 1, 11.13-15); «Circa primum dico quod hoc nomen 'Deus' potest habere diversas descriptiones: una est quod Deus est aliquid nobilius et melius omni alio a se; alia descriptio est quod Deus est illud quo nihil est melius nec perfectius.» Quodlibet I, q.1, a.1 (Wey: p. 1, 11.17-18, p. 2, 11.19-20).

25 «Circa secundum dico quod accipiendo Deum secundum primam descriptionem, non potest demonstrative probari quod tantum est unus Deus. Cuius ratio est quia non potest evidenter sciri quod Deus est, sic accipiendo; igitur non potest evidenter sciri quod tantum est unus Deus, sic accipiendo Deum. Consequentia plana est: antecedens probatur, quia haec propositio 'Deus est' non est per se nota, quia multi dubitant de ea; nec potest probari ex per se notis, quia in omni rationi accipietur aliquod dubium vel creditum; nec est nota per experientiam, manifestum est; igitur etc.» Quodlibet I, q.1, a.2, c.1 (Wey: p. 2, 11.22-31). 
bilidade da existência de Deus, segundo a segunda descrição, isto é, como algo insuperavelmente perfeito. Nesta acepção, a existência de Deus é racionalmente demonstrável por redução ao absurdo. Se, por hipótese absurda, se admitir que não existe algo insuperavelmente perfeito, abrir-se-ia um processo infinito na ordem de perfeição dos entes, isto é, um processo interminável de maior em maior perfeição, o que não é racionalmente tolerável para o filósofo de Ockham ${ }^{26}$. Deste modo, Guilherme situa-se na linhagem da filosofia de Aristóteles, assumindo para a ordem de perfeição dos entes o princípio da finitude da ordem das causas. Mas a demonstrabilidade da existência de algo insuperavelmente perfeito, pelo princípio da finitude da ordem de perfeição dos entes, não assegura por si só que o insuperavelmente perfeito seja algo único. A unicidade de Deus já não é demonstrável, é uma admissão de fé27.

É, portanto, complexa a posição de Guilherme de Ockham na questão da demonstrabilidade ou não da existência de um Deus único: em última análise, Guilherme é duplamente contra a demonstrabilidade da unicidade de Deus, quer seja descrito como algo sumamente perfeito quer como algo insuperavelmente perfeito; no entanto, embora se pronuncie contra a demonstrabilidade da existência de algo sumamente perfeito, seja ou não único, Guilherme admite a demonstrabilidade da existência de algo insuperavelmente perfeito, seja ou não único. É, através desta admissão, que Guilherme de Ockham se revela favorável ao argumento anselmiano do Proslogion. De facto, este argumento defende a existência de Deus, como algo insuperavelmente pensável, ou seja, propondo uma descrição de Deus, que é compatível com a demonstrabilidade da existência de Deus, segundo o filósofo de Ockham. Ora, a descrição de Deus, como algo insuperavelmente pensável, é um conceito negativo de supremo. Portanto, do duplo conceito de supremo, o conotativo e o negativo, só o negativo, o conceito de insuperável, é que consiste com a demonstrabilidade da existência de Deus, com base na inconveniência racional de um processo infinito na busca de algo superior ou mais perfeito. É, com base nesta inconveniência, que Guilherme de Ockham recupera explicitamente, como veremos, a ratio Ansel$m i$, apesar da mediação de Duns Escoto.

Todavia, por que razão é que o conceito conotativo de supremo não é suficiente para a demonstrabilidade da existência de Deus? Acima registámos a seguinte posição de Guilherme: a existência de Deus, como

26 «Sciendum tamen quod potest demonstrari Deum esse, accipiendo 'Deum' secundo modo prius dicto, quia aliter esset processus in infinitum nisi esset aliquid in entibus quo non est aliquid prius nec perfectius.» Quodlibet I, q.1, a.2, c.4 (Wey: p. 3, 11.54-57).

27 «Sed ex hoc non sequitur quod potest demonstrari quod tantum est unum tale, sed hoc tantum fide tenetur.» Quodlibet I, q.1, a.2, c.4 (Wey: p. 3, 11.57-59). 
supremo, não é por si evidente nem demonstrável por razões que não incluam dúvida ou crença. Aprofundemos agora esta posição, que nos permitirá compreender a recensão da ratio Anselmi pelo filósofo de Ockham.

\section{A ratio Anselmi}

Antes de mais, a afirmação da existência de Deus não é uma proposição por si evidente. Porquê? Desde logo porque, como acima vimos, nós não conhecemos Deus em si, como conhecemos em si os acidentes sensíveis, caso em que a existência é inseparavelmente dada com a quididade. Tal como as substâncias sensíveis, Deus não é por nós cognoscível senão em conceito próprio e compósito. Mas neste género de conhecimento em conceito próprio, o dado da existência precede o da essência. Será, então, que também na acepção de Deus em conceito próprio, o conhecimento da existência precede o da essência? Guilherme responde negativamente: nós não conhecemos mais a existência de Deus do que a sua essência. Logo, não conhecemos a existência de Deus antes de conhecermos a sua essência. O conhecimento da proposição "Deus existe" equivale ao da proposição "Deus é uma essência" ou "Deus é uma quididade". Na proposição "Deus existe", o verbo "existir" é apenas um conceito que supõe pela essência divina ${ }^{28}$. Quer isto dizer que há identidade entre existência e essência em Deus? Uma vez que, em Deus, não há distinção real entre os seus atributos, é de admitir que também não haja distinção real entre essência e existência ${ }^{29}$. Daí que a afirmação da existência

28 «Tertium dubium est quia videtur quod quidditas divina possit in se a nobis cognosci, et aliqui nituntur hoc probare» Ord. I, d.3, q.2, p. 406, 11.9-11. «Item, esse est de per se intellectu Dei, sed nos cognoscimus 'esse' inesse quidditati Dei, et non possumus cognoscere compositionem nisi cognitis extremis, igitur possumus cognoscere quidditatem Dei.» Ord. I, d.3, q.2 (Brown e Gál: p. 407, 11.16-19). [Responsiones ad dubia] «Ad aliud dico quod non plus cognoscimus esse Dei quam quidditatem Dei. Unde sicut scimus istam propositionem 'Deus est' ita scimus istam 'Deus est essentia' vel 'Deus est quidditas', et ita cognoscimus terminos unius propositionis sicut alterius, et propter hoc non cognoscimus plus esse Dei quam essentiam Dei. Unde est advertendum quod quando dicimus 'Deus est', ibi non accipitur ipsum esse divinum, sed unus conceptus, sive sit syncategorematicus sive categorematicus, qui modo suo habet supponere pro esse divino, hoc est, pro divina essentia.» Ord. I, d.3, q.2 (Brown e Gál: p. 415, 11.7-15).

29 «Utrum Deum esse sit per se et naturaliter notum» Ord. I, d.3, q.4 (Brown e Gál: p. 432). «Secundum dubium est quia videtur dicere quod esse quod est per se notum de divina essentia sit aliquo modo distinctum a divina essentia, quia videtur dicere quod in tali propositione sunt distincta extrema, et quod praedicatum nulli prius et perfectius convenit quam huic essentiam. Si sic intelligat et accipiat aliquod esse proprium Deo quod prius competit Deo quam aliquod aliud praedicatum, inter quae tamen est aliqua distinctio, hoc non est verum, quia si non est ali- 
de Deus, para os bem-aventurados, que têm a visão beatífica, seja um juízo de identidade por si evidente ${ }^{30}$. No entanto, a quem apenas cabe um conhecimento abstractivo de Deus, como é o nosso caso, a afirmação da existência de Deus não é um juízo de identidade por si evidente. De facto, é um juízo dubitável.

Anselmo quis refutar, através do seu argumento do Proslogion, a dubitabilidade da existência de Deus. Aquele que verdadeiramente compreende o conceito anselmiano de Deus não pode sequer duvidar da sua existência ${ }^{31}$. Já Guilherme de Ockham reconhece que duvidar da existência de Deus é, para nós, uma possibilidade inegável. E tal não se deve a incompreensão alguma de algum conceito de Deus. Para o filósofo de Ockham, a dubitabilidade da existência de Deus decorre da índole dos nossos conceitos de Deus e de existência. Como oportunamente vimos, o conceito próprio que nós conseguimos formar acerca de Deus não é senão um conceito composto de conceitos comuns. Também o conceito de existência, que supõe pela essência divina na proposição "Deus existe", é um

qua distinctio inter divinam essentiam et bonitatem illam vel sapientiam illam quae est realiter divina essentia, multo magis vel aeque non est aliqua distinctio inter essentiam divinam et esse quod est realiter ipsa divina essentia.» $O r d$. I, d.3, q.4 (Brown e Gál: p. 437, 11.3-13).

30 «Secundo, dico quod alius terminus est universale et quodlibet contentum sub eo, sive contentum dicatur res sive conceptus, et eodem modo alius terminus est definitio et definitum. Et secundum hoc dico quod alii termini sunt in ista propositione 'Deus est' quam nos habemus modo de facto, et alii termini sunt in illa propositione quam videns essentiam divinam potest formare, praedicando illud esse quod est divina essentia de ipsamet divina essentia, et aliquis alius terminus est in illa propositione quam potest talis formare praedicando illud idem quod nos praedicamus de divina essentia, ita quod sint ibi duae propositiones ad minus possibiles, quae nobis non sunt possibiles. Secundum hoc dico quod illa propositio quam de facto habemus non est per se nota, sed propositio utraque quam format beatus, sive praedicando esse quod est Deus de divina essentia sive illud quod nos praedicamus, est per se nota. Primum patet, quia illa propositio quae est dubitabilis non est per se nota; sed ista propositio quam nos habemus est dubitabilis, manifestum est; igitur etc. Secundum patet, quia apprehendens illos terminos et formans propositionem necessario assentit rei. De prima patet, quia ibi praedicatur idem de se, scilicet essentia de essentia; sed de re simplici non potest intellectus apprehendens illam rem dubitare quin praedicatio eiusdem de eodem sit vera; igitur etc. De secunda etiam propositione patet, quia intellectus beatus videns illam essentiam non potest dubitare eam esse, nec etiam apprehendens eam abstractive, quaecumque sit ratio istius dicti. Per alteram istarum propositionum est illa propositio quam nos habemus de facto demonstrabilis, praedicando in prima propositione illud praedicatum quod nos habemus de ipsa divina essentia in se; secundo, praedicando de illo subiecto quod nos habemus ipsam divinam essentiam, et ex his propositionibus concludendo praedicatum quod nos habemos de subiecto quod nos habemus.» Ord. I, d.3, q.4 (Brown e Gál: p. 440, 11.1-24, p. 441, 11.1-7).

31 «Sic ergo vere est aliquid quo maius cogitari non potest, ut nec cogitari possit non esse.» Pros. 3 (Schmitt: I, p. 103, 11.1-2). 
conceito comum. Ora nenhum conceito comum se identifica com algum particular que caia sob a sua extensão, pelo que nenhum conceito comum é o conceito próprio ou exclusivo de algo. Na medida em que Deus não é por nós propriamente concebido senão através de conceitos comuns, Deus não é por nós concebido senão juntamente com outros objectos concebíveis através dos mesmos conceitos comuns. Também a existência de Deus não é por nós concebível senão juntamente com outras existências concebíveis sob o conceito comum de existência. Ora ser concebível juntamente com outros concebíveis, através de conceitos comuns, é condição suficiente para algo ser dubitável. Só daquilo de que podemos ter um conhecimento perfeitamente circunscrito é que não podemos duvidar. Tudo aquilo que não é cognoscível senão com base em conceitos comuns é dubitável. Tal é o caso da existência ou da essência de Deus ${ }^{32}$.

Entretanto, a dubitabilidade de algo é também condição suficiente da sua demonstrabilidade. Se a existência de Deus é dubitável, ela é, por isso, também demonstrável ${ }^{33}$. Guilherme de Ockham pronuncia-se clara-

32 «Primum ostendo sic: omnis intellectus cognoscens aliquam naturam in se, nullo alio concurrente in ratione obiecti, potest vere cognoscere illam rem esse in re vel non includere contradictionem, immo non potest dubitare illud obiectum includere contradictionem. Sed viator intelligens Deum notitia incomplexa, quantum est possibile viatori, potest dubitare an includat contradictionem, quia potest dubitare an includat contradictionem Deum esse, etiam posito quod firmiter credat quod nihil est impossibile esse nisi includens contradictionem. Igitur talis non cognoscit Deum in se, modo exposito. Maior videtur manifesta, quia hoc est evidenter notum quod nunquam concipitur aliquid includens contradictionem sine pluribus obiectis conceptis, igitur concipiens tantum unam rem sine pluralitate obiectorum non potest dubitare illam rem includere contradictionem. Minor etiam est manifesta, quia multi dubitant Deum esse et utrum sit possibile Deum esse.» Ord. I, d.2, q.9 (Brown e Gál: p. 313, 11.4-19). «Ad argumentum principale [Quod sic: Quia propositio necessaria in qua praedicatur idem de se est per se nota; sed in ista 'deitas est' praedicatur idem de se, quia esse Dei et deitas in nullo penitus distinguuntur; igitur etc. (Ord. I, d.3, q.4. Brown e Gál: p. 432, 11.5-8)] dico quod in ista propositione 'deitas est' non praedicatur idem de se, quia hic praedicatur unum commune ad Deum et ad alia. Qualiter autem sit commune, ad praesens non curo. Et dictum est prius [supra, d.2, q.7, pp. 255s.] quod nullum commune est idem cum suo inferiori, nec est pars sui inferioris nisi quando plures conceptus coniunguntur, sicut est de definitione et parte definitionis, quia ibi una pars est in plus quam tota definitio, nec etiam in aliquo alio casu inferius includit suum superius, et ideo in tali propositione non praedicatur idem de se, nec pars de toto, - nisi ut dictum est -, nec aliquid intrinsecum illi de quo praedicatur.» Ord. I, d.3, q.4 (Brown e Gál: p. 441, 11.21-24, p. 442, 11.1-7.

33 «Et si quaeratur, cui est ista propositio demonstrabilis, dico quod est demonstrabilis ipsi videnti divinam essentiam vel cognoscenti abstractive ipsam divinam essentiam in se. - Et si dicatur quod talis propositio non est sibi dubitabilis, dico quod posito quod talis manens talis non posset illam propositionem dubitare, tamen est demonstrabilis, quia ad hoc quod aliqua propositio sit demonstrabilis sufficit quod possit dubitari a quocumque, et quod postea per syllogismum accipientem propositiones necessarias possit fieri nota. Et ita est in proposito, quia ali- 
mente a favor da demonstrabilidade da existência de Deus, e é entre as possibilidades de demonstração da existência de Deus que se encontra a ratio Anselmi, tal como é recuperada pelo filósofo fransciscano de Ockham.

Não é desde logo, porém, como um argumento a favor da existência de Deus que Guilherme introduz a ratio Anselmi; é, sim, como um argumento a favor da infinitude de Deus, segundo a interpretação do argumento anselmiano feita já por João Duns Escoto.

Na verdade, o conceito anselmiano de Deus, como algo insuperavelmente pensável, foi desde logo tomado por Duns Escoto, como um conceito de infinito, reportando-se a Proslogion $5^{34}$. No itinerário especulativo de Escoto, o raciocínio de Proslogion 2 aparece integrado na via da eminência a favor da infinitude de Deus, quer na Ordinatio quer no Tractatus de Primo Principio. Entre as variações interpretativas (colorationes) do legado de Anselmo, a primeira coloratio é a mais próxima da letra do texto de Proslogion 2, e é aquela com a qual se configura a retomada do argumento anselmiano por Guilherme de Ockham. O ponto de partida é a definição do conceito de Deus, como algo conhecido ou pensado sem contradição, maior do que o qual não pode ser pensado sem contradição ${ }^{35}$. O ponto de partida é, assim, um conceito através do qual Deus seja pensável sem contradição, e tal é o conceito de insuperavelmente pensável, que interdiz a contradição de ser superável por um pensável maior. No entanto, logo a seguir, Duns Escoto simplifica, abrevia e reduz o conceito de insuperavelmente pensável ao de supremo pensável (summum cogitabile), não deixando de subentender aquele através deste. E, acerca

quis potest istam propositionem dubitare; et si postea videat divinam essentiam potest eandem formare quam prius, et virtute notitiae praemissarum eam evidenter cognoscere.» Ord. I, d.3, q.4 (Brown e Gál: p. 441, 11.8-19).

34 «Praeterea, quo maius nihil cogitari potest, illud esse per se notum est; Deus est huiusmodi, secundum Anselmum, Proslogion, cap. 5; ergo etc. Illud etiam non est aliquod finitum, ergo infinitum.» Ord. I, d.2, p. 1, q.2, n.11 (Ed. Vat.: II, p. 129). O passo anselmiano evocado é o seguinte: «Quid igitur es, domine Deus, quo nil maius valet cogitari?» Proslogion 5 (Schmitt: I, p. 104, 1.11).

35 «Per illud potest colorari illa ratio Anselmi de summo bono cogitabili, Proslogion, et intelligenda est eius descriptio sic: Deus est quo cognito sine contradictione maius cogitari non potest sine contradictione. Et quod addendum sit "sine contradictione" patet, nam in cuius cognitione vel cogitatione includitur contradictio, illud dicitur non cogitabile, quia sunt dua cogitabilia opposita nullo modo faciendo unum cogitabile, quia neutrum determinat alterum.» Ord. I, d.2, p. 1, q.1, n.138 (Ed. Vat.: II, pp. 208-209); «Per illud potest colorari illa ratio Anselmi de summo cogitabili. Intelligenda est descriptio eius sic: "Deus est quo", cogitato sine contradictione, "maius cogitari non potest" sine contradictione. Nam in cuius cogitatione includitur contradictio, illud dicitur non cogitabile, et ita est; sunt enim tunc duo cogitabilia opposita, nullo modo faciendo unum cogitabile, quia neutrum determinat alterum.» $T P P$, c. 4, n.79 (BAC 503: p. 152). 
do supremo pensável, o filósofo afirma que pode ser na realidade, segundo a Ordinatio ${ }^{36}$, ou, simplesmente, que é na realidade, segundo o Tractatus de Primo Principio ${ }^{37}$. Esta diferença não é irrelevante, porquanto a inferência da existência real do ente primeiro, a partir da demonstração da sua possibilidade, é, porventura, o passo mais peculiar e significativo das vias escotistas. De qualquer modo, esse passo está já dado antes da coloratio da ratio Anselmi, nas duas obras consideradas ${ }^{38}$. Além disso, o argumento que serve para provar a possibilidade da existência real do supremo pensável, na Ordinatio, é o mesmo que é usado para provar a existência real do supremo pensável, no Tractatus de Primo Principio, e esse argumento é a razão anselmiana de Proslogion 2.

A coloratio escotista procede, tal como a ratio Anselmi, por redução ao absurdo. Se, por hipótese, o supremo pensável residisse apenas no intelecto, daí decorreria uma contradição: o supremo pensável seria e não seria possível. O supremo pensável, enquanto pensável, seria possível; mas, enquanto exclusivamente residente no intelecto, não seria possível, porque seria causalmente dependente do intelecto, e tal dependência repugna à noção de supremo pensável, incausável como o primeiro eficiente ${ }^{39}$. O supremo pensável não pode existir só no intelecto, como um efeito ou um produto do intelecto, porque ser causalmente dependente entra em contradição com a noção de supremo pensável, como incausável. A existência independente do intelecto, para o supremo pensável, é uma consequência da sua incausabilidade, como causa primeira. O Doutor Subtil reforça a prova com um juízo de ordem, inspirado no juízo anselmiano da ordem da existência no intelecto e na realidade, que opera em Proslogion 2. Referimo-nos à afirmação de que algo na realidade é um pensável maior do que algo no intelecto. Duns Escoto faz mesmo questão de precisar que este juízo de maior deve ser entendido, não para a mesma variável nas duas posições, mas sim para qualquer variável existente relativamente

36 «Summum cogitabile praedictum, sine contradictione, potest esse in re.» Ord. I, d.2, p. 1, q.1, n.138 (Ed. Vat.: II, p. 209).

37 «Sequitur tale summe cogitabile praedictum esse in re» TPP, c.4, n.79 (BAC 503: p. 152).

38 Cf. Ord. I, d.2, p. 1, q.1, n.58 (Ed. Vat. II: pp. 164-165); TPP, c.3, n.33 (BAC 503: pp. 84-86).

39 «Et tunc arguitur ultra quod illud sit, loquendo de esse exsistentiae: summe cogitabile non est tantum in intellectu cogitante, quia tunc posset esse, quia cogitabile possibile, et non posset esse, quia repugnat rationi eius esse ab aliqua causa, sicut patet prius in secunda conclusione de via efficientiae [n.57]» Ord. I, d.2, p. 1, q.1, n.138 (Ed. Vat. II: p. 210); «Ultra de esse existentiae: summum cogitabile non est tantum in intellectu cogitante; quia tunc posset esse, quia cogitabile, et non posset esse, quia rationi eius repugnat esse ab alio, secundum tertiam et quartam tertii [nn.32-33].» TPP, c.4, n.79 (BAC 503: p. 152). 
a alguma outra residente apenas no intelecto ${ }^{40}$. Aquilo que faz esta precisão é uma conversão do juízo anselmiano da ordem da existência, às relações de dependência das ordens causais do ente, que povoam a metafísica escotista: dizer que algo na realidade é um pensável maior do que algo apenas no intelecto é o mesmo que dizer que uma coisa realmente existente, enquanto algo causalmente independente do intelecto, é um pensável maior do que uma coisa residente apenas no intelecto, enquanto algo causalmente dependente do intelecto. Assim entendido, o juízo escotista não é um princípio da ordem da existência, mas um princípio da ordem de dependência do pensável relativamente ao intelecto.

Segundo a versão escotista, a ratio Anselmi é, então, revisitada por Guilherme de Ockham, no âmbito da questão15 do seu Quodlibet VII. A questão 15 pergunta se a infinitude de Deus pode ser provada pela via da eminência ${ }^{41}$, conforme o intentara Duns Escoto. Entre as razões escotistas a favor, figura a ratio Anselmi. De acordo com a razão de Anselmo, aquilo maior do que o qual não pode ser pensado sem contradição é infinito; Deus é aquilo maior do que o qual não pode ser pensado sem contradição; logo, Deus é infinito ${ }^{42}$. Deus, enquanto insuperavelmente pensável sem

40 «Maius ergo cogitabile est quod est in re quam quod est tantum in intellectu. Non est autem hoc sic intelligendum quod idem si cogitetur, per hoc sit maius cogitabile si exsistat, sed, omni quod est in intellectu tantum, est maius aliquod quod exsistit.» Ord. I, d.2, p. 1, q.1, n.138 (Ed. Vat. II: p. 210); «Maius igitur cogitabile est illud quod est in re quam quod in intellectu tantum; non sic intelligendo quod idem, si cogitetur, per hoc sit maius cogitabile, si existat, sed omni quod est in intellectu tantum, est maius aliquod cogitabile quod existit.» TPP, c.4, n.79 (BAC 503: p. 152). Dissemos justamente que este juízo escotista era "inspirado" no juízo anselmiano da ordem da existência, que opera em Proslogion 2, porquanto não coincide verdadeiramente com ele. O juízo anselmiano é um princípio de ordem das duas posições da existência, no intelecto e na realidade, que é solidário com a ordem da essência: algo existente nas duas posições, no intelecto e na realidade, é sempre um pensável maior do que esse mesmo algo existente apenas no intelecto. Assim interpretamos o teor do princípio, que opera no seguinte passo de Proslogion 2: «Et certe id quo maius cogitari nequit, non potest esse in solo intellectu. Si enim vel in solo intellectu est, potest cogitari esse et in re, quod maius est.» (Schmitt: I, p. 101, 11.15-17). As duas posições da existência tornam maior qualquer pensável, mesmo que a existência real de um pensável, como o supremo pensável, seja incomensuravelmente maior do que a sua existência intelectual, enquanto é pensado pelo intelecto humano; e, também, mesmo que a existência intelectual de um pensável, como um acto mau, seja preferível ou qualitativamente maior do que a sua existência real, isto é, do que a sua prática. Por conseguinte, julgamos que o princípio anselmiano da ordem da existência, correlativa da ordem da essência, perde força, ao converter-se num princípio da ordem de dependência causal do pensável relativamente ao intelecto, como acontece na sua variação escotista.

41 «Utrum per viam eminentiae possit evidenter probari quod Deus sit infinitus intensive» Quodlibet VII, q.15 (Wey: p. 755, 11.1-3).

42 «Secundo sic: per rationem Anselmi, Proslogion, cap. 2, illud quo maius cogitari 
contradição, é infinito. Acresce o seguinte raciocínio por redução ao absurdo, similar ao de Proslogion 2: se o supremo pensável sem contradição existe apenas no intelecto que pensa, aquele supremo poderia existir, porque é pensável que exista sem contradição, e não poderia existir, porque repugna ao seu conceito que exista por outro, como seja pelo intelecto. Tal é a contradição, que impede que o supremo pensável exista apenas no intelecto, e que obriga a concluir que o mesmo exista na realidade. Neste raciocínio, o conceito de insuperavelmente pensável aparece reduzido ao de supremo pensável, ou seja, exprimindo-nos nos termos da análise do filósofo de Ockham, o conceito negativo de supremo é reduzido ao conceito conotativo de supremo. O mesmo raciocínio justifica-se pelo seguinte princípio de ordem: é maior aquilo que existe na realidade do que aquilo que existe apenas no intelecto. Este princípio precisa-se à maneira escotista, como um princípio da ordem de dependência do pensável relativamente ao intelecto, de modo que algo existente realmente é maior do que tudo aquilo que existe apenas no intelecto, isto é, apenas por causa do intelecto ${ }^{43}$. Assim é descrita a razão de Anselmo, por Guilherme de Ockham, como um argumento da via escotista da eminência a favor da infinitude divina.

Como é que Guilherme se pronuncia a este propósito? A complexidade da sua posição conduz-nos a analisá-la em três níveis: em relação à questão da demonstrabilidade da infinitude de Deus por via da eminência (questão15); em relação à apropriação escotista da ratio Anselmi a favor da existência de Deus como infinito; e em relação à ratio Anselmi propriamente dita, desvinculada da apropriação escotista. É neste terceiro nível de análise que se encontra o veredicto final do Venerável Inceptor sobre aquele legado do Doutor Magnífico.

Quanto à questão da demonstrabilidade da infinitude de Deus por via da eminência, a posição de Guilherme é contra, porque não há razão suficiente que prove a insuperável eminência de Deus, como infinito; Deus pode ser insuperavelmente eminente ou perfeito e ser, todavia, finito ${ }^{44}$. O

non potest sine contradictione, est infinitum; sed Deus est huiusmodi; igitur etc. Si dicis quod illud non est in re nec tale ens existit, contra: in summo cogitabili summe quiescit intellectus, igitur in ipso est summe ratio sui primi obiecti, scilicet entis.» Quodlibet VII, q.15 (Wey: p. 756, 11.34-39).

43 «Praeterea si summum cogitabile sine contradictione sit tantum in intellectu cogitante, tunc illud summum posset esse, quia est cogitabile esse sine contradictione, et non posset esse, quia rationi eius repugnat esse ab alio. Maius igitur cogitabile est quod est in re quam quod est in intellectu tantum. Non autem intelligo quod idem sit maius per hoc quod existit, sed quod omni eo quod est in intellectu tantum, est maius cogitabile aliquid quod existit.» Quodlibet VII, q.15 (Wey: p. 757, 11.40-47)

44 «Sed istis non obstantibus, teneo oppositum, tum quia non potest sufficienter probari quod Deus sit ens eminentissimum; tum quia potest esse ens eminentissimum, ita 
filósofo de Ockham pronuncia-se assim desfavoravelmente a respeito de todo o empenho da teologia de João Duns Escoto em demonstrar racionalmente o atributo divino da infinitude.

Quanto à apropriação escotista da ratio Anselmi a favor da existência de Deus como infinito, a posição de Guilherme é também e consequentemente contra. Vejamos como. Desde logo, a respeito do conceito de supremo pensável, Guilherme introduz a seguinte distinção: ou o supremo pensável é entendido num pensamento verdadeiro ou o supremo pensável é entendido num pensamento que não inclui contradição. Esta distinção justifica-se porque nem todo o pensamento que não inclui contradição é um pensamento verdadeiro. Logo, o conceito de supremo pensável, entendido apenas num pensamento sem contradição, que não exclui por completo a falsidade, não se ajusta a Deus. Elegível para este efeito, é, no entanto, o conceito de supremo pensável, entendido num pensamento verdadeiro, mas, neste caso, o supremo pensável é superável por um pensável maior sem contradição, ainda que num pensamento falso e fictício ${ }^{45}$. Por conseguinte, nenhum dos dois entendimentos do conceito de supremo pensável vai sem inconveniente: o primeiro, porque não exclui a falsidade; o segundo, porque não exclui a superação.

Cabe aqui referir, aliás, que o próprio Anselmo, na réplica ao seu primeiro crítico, Gaunilo, já tinha advertido da objecção segundo a qual um supremo existente é pensável como não existente e é superável por um pensável maior, mesmo que não exista. Esta possível objecção não terá sido alheia à separação entre os conceitos de supremo e de insuperável, operada na transição do Monologion para o Proslogion. De facto, já não é o conceito de supremo, mas é o de insuperável, aquele que integra o argumento do Proslogion. Como Anselmo esclarece, os dois conceitos não valem o mesmo para o seu argumento: o conceito de supremo existente não entra em contradição com as possibilidades de negação e de

quod nihil sit melius vel eminentius eo, et tamen esse finitum, nec potest oppositum evidenter probari.» Quodlibet VII, q.15 (Wey: p. 758, 11.65-69).

45 «Ad secundum dico quod minor est neganda secundum philosophos. Et ad primam probationem dico quod aliquid esse summe cogitabile potest dupliciter intelligi: vel vera cogitatione, vel cogitatione non includente contradictionem, quia non omnis cogitatio non includens contradictionem est vera cogitatio, sicut cogitare me esse supra astra non includit contradictionem. - Primo modo intelligendo, verum est quod in summo cogitabili summe quiescit intellectus, et in ipso est summe ratio entitatis. Sed isto summo potest maius cogitari sine contradictione cogitatione falsa et ficta. - Secundo modo intelligendo 'summum cogitabile', secundum philosophos est illa neganda: quod intellectus summe quiescit in summo cogitabili cogitatione non includente contradictionem, quia licet secundum philosophos sine contradictione potest cogitari maius Dei, magis tamen quietatur intellectus in vera cogitatione ipsius Dei quam in cogitationem falsa et ficta maioris cogitati.» Quodlibet VII, q.15 (Wey: pp. 759-760, 11.109-125). 
superação, como entra em contradição o conceito de insuperavelmente pensável ${ }^{46}$, em conjunção com os princípios da ordem da existência, que medeiam as principais inferências do argumento do Proslogion. Anselmo não seria, pois, totalmente surpreendido pelas consequências do duplo entendimento do conceito de supremo pensável, segundo Guilherme de Ockham, intérprete de Escoto, na sua apropriação da ratio Anselmi.

Aliás, de modo similar a Anselmo, também Guilherme reconhece que os dois entendimentos do conceito de supremo pensável não valem o mesmo para a aplicação do princípio de ordem, que opera em Proslogion 2. Segundo este princípio, na interpretação de Duns Escoto, algo que exista na realidade é maior do que tudo aquilo que existe apenas no intelecto, na medida em que não existe apenas por causa e na dependência do intelecto. Ora, na interpretação de Guilherme de Ockham, aquilo que existe na realidade não é um pensável maior, entendido num pensamento simplesmente sem contradição, do que aquilo que existe apenas no intelecto, na medida em que um pensamento sem contradição não exclui a falsidade. Portanto, também o supremo pensável, entendido num pensamento simplesmente sem contradição, não é um pensável maior existindo na realidade do que existindo apenas no intelecto. A admissão da superioridade de algo realmente existente a todo o existente apenas no intelecto não é, assim, razão suficiente para ser inferida a existência do supremo pensável, entendido num pensamento sem contradição. Mas tal não é já o caso do supremo pensável, entendido num pensamento verdadeiro. Aquilo que existe na realidade já é um pensável maior, entendido num pensamento verdadeiro, do que aquilo que existe apenas no intelecto. Portanto, também o supremo pensável, entendido num pensamento verdadeiro, é um pensável maior existindo na realidade do que existindo apenas no intelecto. A mesma admissão da superioridade de algo realmente existente a todo o existente apenas no intelecto já permite inferir a existência do supremo pensável, entendido num pensamento verdadeiro ${ }^{47}$. Por conseguinte, só entendido deste modo é que o conceito de supremo pensável torna procedente a ratio Anselmi. Mesmo assim, tal entendimento do

46 «Quid enim si quis dicat esse aliquid maius omnibus quae sunt, et idipsum tamen posse cogitari non esse, et aliquid maius eo etiam si non sit, posse tamen cogitari? An hic aperte inferri potest: non est ergo maius omnibus quae sunt, sicut ibi apertissime diceretur: ergo non est quo maius cogitari nequit?» Quid ad haec respondeat editor ipsius libelli [5.] (Schmitt: I, p. 135, 11.14-18).

47 «Ad secundam probationem dico secundum philosophos quod summum cogitabile cogitatione non includente contraditionem non est in re, quia repugnat Deo quod summum sit. Et ultra dico quod illud quod est in re non est maius cogitabile cogitatione non includente contradictionem quam illud quod est in intellectu tantum, sed bene est maius cogitabile vera cogitatione. Et ideo non probat tale cogitabile summum existere, quo maius non potest cogitari cogitatione non includente contradictionem.» Quodlibet VII, q.15 (Wey: p. 760, 11.126-134). 
conceito de supremo pensável não impede que o mesmo seja superável por um pensável maior, ainda que não existente, num pensamento sem contradição ${ }^{48}$.

Esta recensão crítica, por parte de Guilherme de Ockham, da ratio Anselmi via Escoto suscita algumas considerações. Antes de mais, Guilherme não contesta o princípio da ordem da existência, que opera em Proslogion 2, tal como é interpretado pelo filósofo confrade, a saber, como um princípio da ordem de dependência causal do pensável face ao intelecto. Aquilo que inviabiliza a ratio Anselmi é o entendimento do conceito de supremo pensável apenas num pensamento sem contradição. Já o entendimento do mesmo conceito num pensamento verdadeiro viabilizaria a ratio Anselmi, não fossem dois decisivos inconvenientes: o primeiro, que Guilherme reconhece, é a superabilidade de tal conceito por um pensável maior, ainda que fictício; o segundo, que Guilherme não reconhece, pelo menos explicitamente, é a petição de princípio, que decorre da cláusula de entender o conceito de supremo pensável num pensamento verdadeiro. Com efeito, postulando esta cláusula à partida, admite-se por princípio aquilo que se pretende demonstrar, a saber, a existência do supremo pensável, que é, precisamente, o que permite entender o conceito de supremo pensável num pensamento verdadeiro.

Balanço feito, Guilherme de Ockham toma uma posição desfavorável relativamente à apropriação escotista da ratio Anselmi a favor da existência de Deus como infinito. A este nível, Guilherme é um crítico do argumento anselmiano via Escoto.

Mas há um terceiro nível de análise, em que a ratio Anselmi é retomada, mas já separadamente da apropriação escotista. Agora Guilherme interroga-se acerca do valor probatório da ratio Anselmi, respeitando desde logo a formulação perifrástica do nome divino de Proslogion 2: «aquilo maior do que o qual não pode ser pensado» ${ }^{49}$. A sua resposta abre com mais uma distinção entre dois modos de entender esta expressão: um modo, segundo o qual algo maior não pode ser pensado de facto; outro modo, segundo o qual algo não pode ser pensado, que seria maior, caso existisse. Trata-se da distinção entre aquilo que é insuperavelmente pensável de facto e aquilo que é insuperavelmente pensável de modo apenas putativo. Só o conceito daquilo que é insuperavelmente pensável de facto permite recuperar a ratio Anselmi, segundo o filósofo de Ockham. Assu-

48 «Ad confirmatione dico quod tantum probat quod perfectissimum cogitabile cogitatione vera existit, et hoc concederet philosophus. Sed tamen maius potest ficte cogitari cogitatione non includente contradictionem.» Quodlibet VII, q.15 (Wey: p. 760, 11.135-138).

49 «Et si dicis: quid igitur probat illa ratio Anselmi, Proslogion, cap. 2, ubi nititur ostendere quod illud quo maius cogitari non potest est in re?» Quodlibet VII, q.15 (Wey: p. 760, 11.139-141. 
mindo o princípio de que nada que não existe na realidade é maior de facto do que aquilo que existe na realidade, Guilherme conclui, com Anselmo, que aquilo maior do que o qual não pode ser pensado existe na realidade, ou seja, que o insuperavelmente pensável de facto existe realmente. É de notar que o princípio, à luz do qual se extrai esta conclusão, é uma versão derivada do princípio da ordem da existência, que opera em Proslogion 2; uma versão próxima mas distinta da de João Duns Escoto, que entendera o mesmo, como um princípio da ordem de dependência do pensável face ao intelecto: na versão de Guilherme de Ockham, o princípio anselmiano transforma-se de facto no princípio da superioridade de um existente a todo o inexistente. Desaparece a referência ao intelecto e sublinha-se o valor da existência. Mas tal princípio não é a única razão que sustenta a conclusão da ratio Anselmi, segundo Guilherme. Há outra razão não menos ponderosa, que é a inconveniência racional de um processo infinito na busca de algo maior entre as coisas existentes. Esta inconveniência postula a necessidade de parar num insuperável ${ }^{50}$. Há, pois, duas fortes razões, que justificam a recuperação da ratio Anselmi por Guilherme de Ockham: o princípio da superioridade de um existente a todo o inexistente, isto é, a afirmação do valor da existência, e o princípio da finitude da ordem da eminência, ou da perfeição.

Tal como anunciara no Quodlibet I (q.1, a.2, c.4), Guilherme de Ockham toma afinal uma posição favorável ao argumento anselmiano, com base em três razões fundamentais: o conceito de Deus, como insuperavelmente pensável de facto; a afirmação do valor da existência; e a rejeição da infinitude da ordem da eminência. Mas estas são também três razões de fundo, que Guilherme partilha com Anselmo e com Escoto, não obstante o intento algo obsessivo de discordar deste seu confrade. Na verdade, a recuperação da ratio Anselmi exigiu algum afastamento da interpretação escotista.

Entretanto, a ratio Anselmi visada é apenas a de Proslogion 2, mas o argumento anselmiano desenvolve-se e termina em Proslogion 3. Guilherme de Ockham mostra não ignorar esse desenvolvimento, na medida em que também se interroga acerca do valor probatório da ratio Anselmi em Proslogion 3, reconstituindo com assinalável fidedignidade essa parte

50 «Respondeo: aliquid esse illud quo maius cogitari non potest, potest dupliciter intelligi: uno modo, quod nihil quod potest cogitari sit maius de facto; alio modo, quod non potest cogitari aliquid quod, si esset, esset maius. Primo modo intelligendo, bene probat ratio Anselmi. Sic formata 'nihil quod non existit in re est maius de facto eo quod existit in re, igitur illud quo maius cogitari non potest existit in re' bene sequitur, supposito quod in rebus existentibus non sit processus in infinitum in maius et maius. Et ultra si illud quo maius cogitari non potest existit in re, cum maximum eorum quae cogitantur sit Deus secundum omnes, sequitur quod Deus existit in re.» Quodlibet VII, q.15 (Wey: p. 761, 11.142-152). 
do argumento anselmiano, mas não chega a responder ${ }^{51}$, de modo que não nos deixou uma posição explícita. O argumento anselmiano, em Proslogion 3, conclui que a existência de Deus é de tal modo necessária que é indubitável. Atendendo à posição de Guilherme de Ockham na questão da demonstrabilidade ou não da existência de Deus, é de suspeitar que assumisse uma posição desfavorável à razão anselmiana de Proslogion 3. Como vimos, Guilherme advoga que a existência de Deus é demonstrável porque é dubitável, pelo que não poderia consistentemente adoptar um argumento para demonstrar que a existência de Deus é indubitável. Julgamos, pois, que o teor de Proslogion 3 colheria um crítico contra da parte de Guilherme de Ockham. A sua omissão compreende-se, porventura, porque o Venerável Inceptor estaria mais empenhado em desconstruir o edifício especulativo do Doutor Subtil do que em ferir o prestígio do Doutor Magnífico.

\section{RESUMO}

Admitindo que Deus é humanamente cognoscível, não em si, mas em conceito, Guilherme de Ockham reflecte com acuidade sobre a natureza dos conceitos que formamos acerca de Deus. Aí detectamos a reelaboração de elementos anselmianos, como a associação e a dissociação entre os conceitos de supremo e de insuperável. Ponderando, aliás, sobre os conceitos constituintes da proposição «Deus existe», o filósofo franciscano pronuncia-se a favor da sua demonstrabilidade. Neste enquadramento, insere-se a recepção do argumento anselmiano, ao qual Guilherme chama ratio Anselmi, na esteira de João Duns Escoto. É, de facto, por mediação do Doutor Subtil, que o filósofo de Ockham retoma criticamente o mais revisitado legado do Doutor Magnífico. Duns Escoto tinha adoptado a ratio Anselmi, de Proslogion 2, como um argumento a favor da infinitude de Deus. Guilherme é um crítico incisivo das vias escotistas de demonstração do atributo divino da infinitude, mas não afasta completamente a possibilidade de demonstrar a existência de um insuperável finito, na esteira da interpretação escotista da ratio Anselmi.

51 «Sed quomodo tunc valet ratio quam facit, cap. 3, ad probandum quod illud quo maius cogitari non potest, non potest cogitari non esse? Et sic arguit: possibile est cogitare aliquid quod non potest cogitari non esse; et illud maius est quam quod potest cogitari non esse; igitur illud quo maius cogitari non potest, non potest cogitari non esse. - Respondeo ... [Responsio deficit]» Quodlibet VII, q.15 (Wey: p. $761,11.153-159)$. 


\begin{abstract}
Admitting that God is humanly knowable, not in himself, but in concept, William of Ockham examines accurately the nature of our concepts about God. We find here the remaking of anselmian elements, like the attachment and the detachment between the concepts of supreme and insuperable. Then considering the concepts involved in the proposition "God exists", the Franciscan philosopher takes position for its demonstrability. Within his position takes place the reception of the anselmian argument, which is called the "ratio Anselmi", in the wake of John Duns Scotus. As a matter of fact, it is through the Doctor Subtilis that the philosopher of Ockham revisitates critically the most well known bequest of the Doctor Magnificus. Duns Scotus had assumed the ratio Anselmi of Proslogion 2, as an argument for God's infinity. William is an incisive critic of the scotist ways of demonstration of God's infinity, but he does not exclude completely the possibility of demonstrating the existence of a finite insuperable, in the wake of the scotist interpretation of the ratio Anselmi.
\end{abstract}

